\title{
Transições cotidianas entre a família e a escola: atividades e relações de crianças nesses contextos ecológicos
}

\section{Daily transitions between home and school: activities and relationships of children in these ecological contexts}

\section{Transiciones diarios entre hogar y la escuela: actividades y relaciones de los niños estos contextos ecológicos}

\author{
Maureanna Cardoso Alvão* \\ Universidade Federal do Pará - UFPA, Belém, Pará, Brasil \\ Lília Iêda Chaves Cavalcante** \\ Universidade Federal do Pará - UFPA, Belém, Pará, Brasil
}

\begin{abstract}
RESUMO
A partir do conceito de transição ecológica (TE), no escopo da Psicologia do Desenvolvimento, este estudo objetivou compreender as mudanças de ambiente, atividades, relações e papeis que marcam o início da vida escolar do ponto de vista da criança. Foram entrevistadas 46 crianças de uma escola pública, de três a quatro anos de idade, em Belém/PA. Os resultados revelaram que durante os percursos de ida à escola e volta para a casa as crianças demonstraram tanto sentimento de bem-estar/alegria (envolvimento da mãe e outros familiares nas rotinas diárias, relacionamentos iniciados no ambiente escolar) como mal-estar/tristeza (queixas de dor e outros sintomas de doenças, referência à violência). Este estudo pode ser útil para ampliar o conhecimento sobre esta e outras transições ecológicas vividas na infância, com destaque para o processo de adaptação da criança no início da vida escolar.
\end{abstract}

Palavras-chave: transição ecológica, criança, atividades, relações.

\begin{abstract}
The purpose of this study was to examine the environmental changes, activities, relationships and roles that mark the beginning of children's school life as they are perceived by themselves. A total of 46 children were interviewed, ages ranging from 3 years to 4 and all of them studying at the same public school in Belém, PA. The results revealed that the children demonstrated both a sense of well-being/joy (mother and other relatives involvement in daily routines, relationships created in the school environment) and ill-being/sorrow (pain complaints and other illness symptoms, references to violence) regarding going to school and going back home. This study may be useful to expand knowledge about this ecological transition and other ones experienced in childhood with emphasis on the child's adaptation process at the beginning of school life.
\end{abstract}


Keywords: ecological transition, child, activities, relationships.

\begin{abstract}
RESUMEN
Desde el concepto de transición ecológica (TE) en el ámbito de la psicología del desarrollo de este estudio tuvo como objetivo comprender los cambios del entorno, actividades, roles y relaciones que marcan el inicio de la vida escolar desde el punto de vista del niño. 46 niños de escuela pública fueron entrevistados, de tres a cuatro años, en Belém / PA. Los resultados mostraron que durante los viajes de ir a la escuela y de regreso a la casa, los niños demostraron tanto sentimiento bienestar/alegría (con la participación de la madre y otros miembros de la familia en las rutinas diarias, las relaciones comenzaron en el entorno de la escuela) como malestar/tristeza (quejas de dolor y otros síntomas de las enfermedades hacen referencia a la violencia). Este estudio puede ser útil para ampliar el conocimiento sobre esta y otras transiciones ecológicas experimentadas en la niñez, especialmente la adaptación del niño al comienzo de la vida escolar.
\end{abstract}

Palabras clave: transición ecológica, niño, actividades, relaciones.

\title{
1 Introdução
}

\subsection{Os microssistemas família e escola e sua importância no desenvolvimento}

A Bioecologia do Desenvolvimento Humano se apresenta à Psicologia como um modelo teórico que integra conhecimentos de diferentes áreas ao definir a noção de desenvolvimento-no-contexto, associando-o a padrões de atividades, relações e papeis vivenciados pela criança em seu ambiente imediato, mas em sintonia com dimensões remotas (ambientes além do imediato) da vida social. Para Bronfenbrenner (2011), o principal expoente dessa perspectiva teórica, o desenvolvimento deve ser entendido como uma mudança duradoura na maneira pela qual a pessoa percebe e lida com o seu ambiente ecológico.

Nesses termos, segundo Bronfenbrenner (1996), a família representa um potente e universal ambiente primário gerador de desenvolvimento nas sociedades humanas, já que esse contexto pode propiciar à criança contato com o mundo simbólico da linguagem e da aprendizagem, contribuindo para o seu amadurecimento cognitivo, motor, emocional e social. Nessa direção, Silva e Tokumaru (2008) afirmam que as figuras parentais compartilham mais os cuidados com os filhos em idade escolar do que qualquer outro membro da família na mesma condição. Ecke (2010) lembra que tem sido função da família, ou mais precisamente dos pais, educar e preparar a criança para o estabelecimento de outras relações que transpõem o domínio do familiar à medida que for crescendo, auxiliando-a no desenvolvimento de autonomia, independência e responsabilidade. Entre os domínios alheios ao familiar, destaca-se a escola, que, 
conforme Dowbor (2008), irá assumir com o passar dos anos um papel de notável importância para a criança, uma vez que, assim como a família, será responsável por veicular parte dos valores éticos, políticos, sociais e morais que acompanharão a criança em seu desenvolvimento.

Do ponto de vista bioecológico, quando se dá a inserção da criança no mundo escolar, uma experiência cada vez mais comum na atualidade, começam a ser processadas não apenas mudanças na configuração do seu ambiente imediato até então formado basicamente pela família, mas também alterações associadas ao modo como são configurados os papeis sociais, as atividades cotidianas e o padrão das relações interpessoais com a formação desse novo microssistema. Em termos conceituais, esse movimento pode ser visto como uma importante transição ecológica que ocorre particularmente com 0 início da vida escolar na infância (Bronfenbrenner, 1996; 2011).

\subsection{A inserção da criança na escola: um mesossistema em formação}

Com o ingresso da criança em instituição voltada à educação infantil, o seu ambiente ecológico se amplia e se coloca para ela um novo microssistema, que tem um padrão próprio de atividades, relações e papeis. Isso quer dizer que uma vez na escola, "a criança terá que aprender a lidar com esses novos elementos, assumindo novas condutas de acordo com as exigências desse novo contexto" (Nunes, 2012, p. 114). Com o início da vida escolar da criança, observa-se que as características físicas e materiais que definem um e outro ambiente passam a estabelecer relações entre si, com a presença de elementos próprios que irão se aproximar e se complementar. Segundo Ladd (2012, p. 9), "crianças que já têm habilidades para fazer amigos e comportamentos cooperativos têm melhores chances de construir relacionamentos aprobativos no contexto escolar e que possam ajudá-las a ter sucesso na pré-escola e no ciclo inicial do ensino fundamental".

$\mathrm{Na}$ perspectiva da Bioecologia do Desenvolvimento Humano (Bronfenbrenner, 2011), a gestão da relação entre família e escola varia conforme as situações, os sistemas e as tradições envolvidas, dependendo particularmente da representação do papel que a instituição escolar cumpre no desenvolvimento infantil do ponto de vista dos pais e da criança. Desse modo, o poder que os pais podem exercer na creche ou pré-escola depende muito de suas expectativas, representações sociais e experiência pessoal de escolarização, que, por sua vez, estão associados ao seu nível social e da comunidade cultural a que pertencem.

Bronfrenbrenner (2011) afirma que o princípio de interconectividade 
é percebido não apenas dentro dos contextos (no caso, a família e a escola), mas com igual força e consequência nas relações por eles estabelecidas - o mesossistema. No presente estudo, para melhor compreender a relação mesossistêmica entre família e escola, optouse por se investigar os processos de transição ecológica vividos pela criança à proporção que deixa o convívio exclusivo na família e se insere em outro microssistema - a escola. Entende-se ainda que a noção de transição ecológica envolva a percepção muitas vezes contrastante desse ambiente institucional com as características peculiares à família, o inédito papel de aluno, a variedade das atividades e as novas relações que passarão a envolver com professores e colegas de classe.

\subsection{O conceito de transição ecológica}

Entende-se que o conceito de transição ecológica por ter sido formulado no escopo de uma teoria do desenvolvimento humano, se aplica a estudos que pretendem, como este, investigar a percepção que a criança tem de sua inserção e adaptação à escola como um contexto ecológico que se diferencia do ambiente familiar. Vogler, Crivello e Woodhead (2008) afirmam que o termo transição tem uma variedade de significados que não cabe em uma única definição, mas que esta compreende processos fundamentais que ocorrem em períodos específicos durante a vida, e estão muitas vezes ligados, entre outras coisas, às mudanças de atividades, papéis, relações e ambiente. Em processos de transição ecológica, os pensamentos e sentimentos da pessoa podem ser alterados na medida em que ocorrem mudanças de ambiente, papel, ou ambos (Bronfenbrenner, 1996).

O desenvolvimento da pessoa é influenciado assim pelas atividades cotidianas realizadas nos vários ambientes que frequenta e na companhia de diferentes pessoas, exercendo assim papeis os mais diversos na ecologia do desenvolvimento. É possível reconhecer trocas no papel social associadas à criança em razão das mudanças de ambiente e do tipo de atividade que o caracteriza. Por exemplo, nas atividades domésticas, que envolvem tudo que está associado ao núcleo familiar da criança, como quando assiste a desenhos animados na televisão, brinca em casa, realiza atividades de vida diária (escovar os dentes, tomar banho, trocar de roupa, calçar os sapatos, etc.), observa-se que ela está no exercício do papel de filho e realiza atividades que Ihes são características. Enquanto que, quando a criança se dedica às atividades escolares, incluindo assistir às aulas, copiar as tarefas no caderno, fazer as provas escritas, entre outras, ela está imbuída do papel de aluno e desempenha próprias desse espaço.

Neste estudo, considera-se que definir com clareza a transição 
ecológica como um termo fundamental na pesquisa e a compreensão desse tema de forma mais abrangente, torna-se uma exigência da atualidade, posto que, desde os anos iniciais, esses processos estão presentes na trajetória de vida da pessoa em desenvolvimento em configurações cada vez mais complexas. A inserção na escola pode ser vista como uma transição normativa, uma vez que é esperado que a criança, que geralmente já convive com a sua família, comece a frequentar a escola (Bronfenbrenner, 2011).

Segundo Vogler, Crivello e Woodhead (2008), as transições exigem importantes ajustes psicossociais e culturais, cognitivos, sociais e emocionais, que dependerão da natureza e as causas da mudança que está em processo, da vulnerabilidade ou resiliência dos indivíduos envolvidos e do grau de mudança e continuidade nas experiências vivenciadas. Os autores fazem a consideração de que todos esses temas são relevantes e que devem suscitar questionamentos para a pesquisa em desenvolvimento humano.

Entretanto, se este tipo de abordagem teórica do tema ainda é pouco comum até hoje, o mesmo não se pode dizer das investigações dedicadas a compreender os processos que envolvem a adaptação da criança à creche ou pré-escola, reconhecendo que são várias as mudanças pessoais e contextuais envolvidas. Em função disso, propõem-se, neste estudo, recuperar investigações que apesar de não terem sido feitas sob a perspectiva bioecológica, trazem elementos teóricos para a discussão dos processos adaptativos vividos pela criança no início da vida escolar, e oferecem evidências das alterações havidas no seu padrão de atividades, relações e papeis.

\subsection{A inserção escolar e adaptação à escola como transição ecológica}

A adaptação da criança à escola se apresenta como um tema que tem ocupado um lugar de destaque em discussões sobre a transição vivida por ela quando deixa de estar e pertencer apenas à família e passa a fazer parte também de outro contexto - a escola. Nesse sentido, a melhor maneira de se entender o valor da preparação no processo de adaptação da criança e como isso se dará no momento do seu ingresso na escola é lembrar que existe uma relação de complementaridade entre ela e as instituições destinadas a atendê-la. Concordando com Kagan (2008), entende-se que a adaptação da criança à escola é fundamental nesse processo de transição, e que, por isso, deve ser vista em uma perspectiva bioecológica, considerando o envolvimento de todos com os quais ela convive na família e os que a recebem na escola (pais, professores e a própria criança). Elas compreendem significativas alterações psicológicas e comportamentais, que, consequentemente, levarão o indivíduo a se 
reorganizar nesse processo de mudança. Conforme Rizzo (2000): vômitos, febre, diarréia, alergias, entre outros, são sinais de alerta. Ecke(2010): É comum a mãe levar o filho pela primeira vez à escola. Para Cruz (2010), fazer pesquisas sobre a adaptação da criança à escola não é propriamente algo novo. O que parece novo é a compreensão de que hoje, mais do que antes, é importante ouvir as crianças sobre como elas vivenciam essa transição em seu cotidiano. Ou seja, "O que é inovador é o aumento na produção científica que toma crianças como sujeitos (...) para conhecer o que elas pensam e sentem sobre temas que lhe dizem respeito." (Cruz, 2010, p. 11).

Nesse sentido, Campos (2008) argumenta que pode ser considerada uma tendência atual na investigação científica, captar a visão das crianças, dando voz à elas, sendo para as menores de seis anos mais adequada a categoria de respondentes (informantes). Na tentativa de se conhecer mais sobre o processo de transição ecológica que marca o início da vida escolar, e assim compreender melhor a vivência dos processos adaptativos pela criança e seus cuidadores (pais e professores), surgiram inquietações referentes ao modo como a criança vivencia a transição ecológica da família à escola no início da vida escolar e como a percebe em meio a idas e vindas de casa para escola e da escola para casa em dias subsequentes.

\section{Método}

\subsection{Caracterização da Instituição}

O estudo foi realizado em uma instituição filantrópica destinada à educação infantil, na cidade de Belém do Pará. Sua manutenção tem sido assegurada por meio de convênios com órgãos gestores da política educacional em nível estadual e municipal, assim como doações espontâneas e promoções realizadas pela instituição. $O$ regime de funcionamento é integral e as crianças frequentam de $2^{\mathrm{a}}$ a $6^{\mathrm{a}}$, no horário de $7 \mathrm{~h} 30 \mathrm{~min}$ às $17 \mathrm{~h} 30 \mathrm{~min}$. A instituição funciona como pré-escola, com turmas de Jardim I, II e III, pela manhã e à tarde.

\subsection{Participantes}

Participaram crianças, de três a quatro anos de idade, que frequentavam as turmas do Jardim I. Foram envolvidos alunos de três turmas: 25 crianças na turma 1, 21 na turma 2 e mais 22 na turma 3. Das 68 crianças que compunham estas turmas, 46 aceitaram participar da pesquisa, o que corresponde a uma amostra de $67,65 \%$ do total. Quanto à formação dos participantes, a criança deveria atender aos seguintes critérios: ser de ambos os sexos, ter de três a sete anos, estar matriculada no Jardim I e frequentando 
regularmente a escola, assim como a sua participação ter sido autorizada por seus pais e/ou responsável legal e ter expressado concordância em participar da pesquisa. Foram excluídas crianças que não atenderam os critérios previamente estabelecidos. Ao final, fizeram parte da amostra 46 crianças do Jardim I, por ser esta uma série que marca o início da vida escolar, cujos pais e elas próprias tivessem concordado com a participação na pesquisa.

\subsection{Ambiente}

O questionário foi aplicado junto às crianças nas dependências internas da escola, mas, sobretudo, em ambientes como os dormitórios infantis e a sala dos professores.

\subsection{Instrumentos e materiais}

As crianças foram ouvidas por meio de questionário, que continha perguntas abertas e fechadas. O instrumento Questionário Entrevista com a Criança $(Q E C)$, elaborado pela autoria deste estudo. É composto por 26 perguntas, sendo dezoito abertas e oito fechadas, organizadas em tópicos. O Tópico I, "Dados pessoais", possui nove itens: 1) Qual é o nome da criança. 2) Qual é o sexo da criança. 3) qual é a idade da criança. 4) Em qual série a criança está matriculada. 5) Em qual turno a criança estuda. 6) Qual é a professora da criança. 7) Qual é o nome do responsável familiar da criança. 8) Qual é o endereço da criança e 9) Qual é o bairro que a criança mora. O Tópico II, "Família Antes da Escola (FAE)", com cinco itens: 1) Pergunta sobre a percepção da criança de onde ela mora. 2) Referente à rotina da criança, se faz atividades, quem acompanha as crianças nessas atividades, e o turno em que são realizadas. 3) Quem prepara a criança em casa para ir à escola. 4) O que a criança faz antes de sair de casa para ir à escola; e 5) Como a criança se sente quando está saindo de casa para ir à escola. O Tópico III, "Trajeto de ida para a escola", envolve seis itens: 1) Quem acompanha a criança para escola. 2) Qual é a condução da criança. 3) O que a criança vê no caminho de casa pra escola. 4) O que a criança faz no caminho de casa pra escola. 5) Quem a criança espera encontrar quando chega à escola; e 6) Como a criança se sente quando está chegando à escola. Por sua vez, o Tópico IV, "Escola", tem sete itens: 1) Onde a criança estuda. 2) O que a criança faz assim que chega à escola. 3) Como a criança se sente quando chega à escola. 4) Se a criança faz atividades, quem acompanha a criança nessas atividades, e em que turno são realizadas. 5) Quem prepara a criança para voltar pra casa. 6) O que a criança faz antes de sair da escola e ir para casa e 7) Como a criança se sente quando está saindo da escola e voltando pra casa. E finalmente, o Tópico V, "Trajeto de volta para casa", com seis 
itens: 1) Qual condução da criança na volta para casa. 2) Quem acompanha a criança para casa. 3) O que a criança vê no caminho da escola pra casa. 4) O que a criança faz no caminho da escola pra casa. 5) Quem a criança espera encontrar quando chega em casa e 6) Como a criança se sente quando está chegando em casa. E por fim, o Tópico VI, "Família Depois da Escola (FDE)", com dois itens: 1) O que a criança faz assim que chega em casa e 2) Como a criança se sente quando chega em casa.

\subsection{Procedimento da pesquisa}

\section{Procedimentos éticos}

Inicialmente foi obtida a autorização para realização da pesquisa na escola por parte da direção da instituição. O projeto foi aprovado pelo Comitê de Ética em Pesquisa (CEP) sob o protocolo no 061/2011. Em seguida, foi solicitada a autorização dos pais e/ou responsável das crianças, após esclarecimentos sobre os propósitos do estudo, leitura e assinatura do Termo de Consentimento Livre e Esclarecido (TCLE).

\subsubsection{Coleta dos dados}

A equipe de pesquisa foi composta por quatro pessoas, uma aluna do Mestrado pelo Programa de Pós-Graduação em Teoria e Pesquisa do Comportamento da Universidade Federal do Pará, e mais três alunas da Faculdade de Psicologia da mesma instituição.

A aplicação do questionário ocorreu logo depois de um período de habituação dos pesquisadores na instituição, e realização de um estudo piloto. A abordagem foi feita no espaço da sala de aula, após a liberação das crianças pelas professoras, presentes no momento. Em seguida, as crianças eram informadas em uma linguagem acessível sobre o procedimento da pesquisa do qual tomariam parte, mantendo com elas uma conversa cordial sobre o tema, a fim de tranquilizá-las e reduzir-lhe a ansiedade e o medo diante de uma situação estranha como pode ser compreendida a sua participação na pesquisa. Houve variação no tempo da entrevista, dependendo de cada criança, mas, em média, teve duração de 40 minutos. Algumas vezes a entrevista foi concluída no mesmo dia, e em outras na data acertada segundo a conveniência da criança. Durante a realização da entrevista, se assim o quisessem, as crianças eram liberadas para merendar, ir ao banheiro, e fazer qualquer outra necessidade, sendo a coleta retomada a seguir. Quanto às dificuldades e desafios encontrados, destaca-se que durante o período da coleta de dados algumas crianças faltavam à escola, responderam as perguntas do questionário com maior quantidade de tempo do que outras, por vezes dispersavam com outros assuntos, não ficavam sentadas na 
cadeira por muito tempo, e se deslocavam na sala, o que exigiu das entrevistadoras retomarem algumas vezes as questões de forma a facilitar a compreensão, acompanhando e respeitando o ritmo das crianças.

\subsubsection{Análise dos dados}

Para análise dos dados coletados por meio da aplicação do questionário, primeiramente foram organizadas planilhas eletrônicas com base no programa Microsoft Office Excel. Com isso houve o armazenamento das respostas dos participantes às perguntas abertas contidas no instrumento. Depois, utilizando-se do SPSS, foi feito o tratamento estatístico dos dados obtidos com o questionário a partir de procedimento analítico de cunho descritivo (frequência simples ou acumulada).

Os dados extraídos foram organizados em torno dos elementos constituintes do ambiente em uma perspectiva ecológica, tais como: Ambientes: Família Antes da Escola (FAE), Trajeto Família-Escola (TFE), Escola (E), Trajeto da Escola-Família (TEF), Família Depois da Escola (FDE); Atividades: rotinas e práticas de cuidado realizadas nesses ambientes ecológicos, com o envolvimento de diferentes pessoas; Relações: pessoas que representam as figuras de cuidado e com presença nas atividades diárias da criança; Papeis: expectativas associadas ao desempenho das crianças nos ambientes e nas relações.

\section{Resultados}

Neste artigo, foram descritas atividades e relações que caracterizam a transição ecológica vivida cotidianamente por crianças no contexto pesquisado. Foram extraídos e organizados os dados que remetem aos cinco ambientes ecológicos, nos moldes em que define Bronfenbrenner $(1996 ;$ 2011), com base em uma perspectiva espaçotemporal: Família Antes da Escola (FAE); Trajeto da Família-Escola (TFE); Escola; Trajeto da Escola-Família (TEF); Família Depois da Escola (FDE).

\subsection{Perfil sociodemográfico das crianças que participaram da pesquisa $(n=46)$}

Observou-se que a maioria delas era do sexo masculino $(58,7 \%)$, tinha quatro anos de idade $(69,6 \%)$, residia no bairro Curió-Utinga $(67,3 \%)$, e pertencia à Turma 1 da série escolar Jardim I, a única das três existentes que possuía uma professora em tempo integral $(43,5 \%)$. 


\subsection{Transitando entre ambientes, atividades, relações e papeis no cotidiano}

Para verificar as atividades e relações no cotidiano das crianças, o cálculo da frequência teve como referência o número de crianças $(n=46)$ e a quantidade de vezes que determinada categoria de resposta foi mencionada.

\subsubsection{Na família antes da escola (FAE): rotinas e atividades de preparação}

Nesse período, durante a preparação das crianças para a sua ida à escola, as três pessoas mais lembradas como companhia nessas atividades foram: mãe (209), sozinha (150), pai (45), além da avó (27), já as menos citadas foram irmãos (1), avô (1) e irmão (3). Na Tabela 1, vê-se que quando indagadas "Como você se sente quando está saindo de casa pra ir à escola?", as crianças apresentaram o seu ponto de vista. Elas mencionaram mais sentimentos que denotam bem estar/alegria (18) do que mal estar/tristeza (13).

Tabela 1.

Categorias que descrevem os sentimentos relatados pelas crianças relacionados ao periodo denominado Familia Antes da Escola (FAE), segundo dados coletados na ECCSI Belem, $2012(n=46)$.

\begin{tabular}{|c|c|}
\hline Categorias & Visão da criança \\
\hline & $\begin{array}{l}\text { "Eu se sinto bem, a minha mãe faz o devê, ela } \\
\text { também foi pra escola, a minha mãe" }\end{array}$ \\
\hline Bem/Alegre/Sem & "Eu não queria vim pra escola, que eu ia chorar, mas \\
\hline Sintomas (18) & $\begin{array}{l}\text { agora eu quero conversar" } \\
\text { "Feliz, porque toda vez que eu venho, eu nem venho } \\
\text { chorando" }\end{array}$ \\
\hline & $\begin{array}{l}\text { "Se sinto que eu quero ficar em casa, porque eu sinto } \\
\text { saudade da minha mãe" }\end{array}$ \\
\hline Mal/Triste/C & $\begin{array}{l}\text { "Com frio. Quando eu saio de casa vem frio, mas } \\
\text { daqui a pouco vem o sol" }\end{array}$ \\
\hline Sintomas (13) & "Dor de cabeça, dor de barriga, dor na perna" \\
\hline & $\begin{array}{l}\text { "Triste quando vem pra escola, porque a mamãe me } \\
\text { bate quando eu venho pra cá, aqui, atrás da cabeça } \\
\text { com a mão, pú [pou!]" }\end{array}$ \\
\hline Não sente nada (2) & "Não sinto nada" \\
\hline $\begin{array}{l}\text { Náo soube informar } \\
\text { (13) }\end{array}$ & "Não sei" \\
\hline
\end{tabular}

\subsubsection{No trajeto da família-escola (TFE): o que faz e como se sente}


Quando perguntado às crianças "Quem acompanha você no caminho de casa para a escola?", entre as respostas mais comuns podem ser apontadas: mãe (36), pai (11), pais (5) e avó (5). Por sua vez, as categorias menos citadas foram: sozinha (2), outros (2) e avós (1). Com relação ao meio de transporte utilizado observa-se que quando perguntado às crianças "Como você vem de casa pra escola?", os três transportes mais mencionados foram: ônibus (18), a pé (17) e bicicleta (13), já os transportes menos mencionados foram carro (12) e moto (7).

A frequência das respostas dadas à pergunta "Como você se sente quando está chegando à escola?" está demonstrada na Tabela 2. As crianças mencionaram mais vezes sentimentos e emoções que denotam satisfação ou expectativa com a proximidade da escola, como por exemplo, os que estão reunidos na categoria bem estar/alegria (23). Com menor frequência, foram apontadas respostas que expressam mal estar/tristeza (18).

Tabela 2.

Frequência das categorias que descrevem os sentimentos relatados pelas crianças relacionados ao periodo Trajeto da Familia-Escola (TFE), segundo dados coletados na ECCSI. Belém, $2012(n=46)$.

\begin{tabular}{|c|c|}
\hline Categorias & Visão das Crianças \\
\hline \multirow[t]{4}{*}{ Bem/Alegre/Sem Sintomas (23) } & "Eu se sente bem" \\
\hline & "Melhor" \\
\hline & "Fico feliz" \\
\hline & "Eu sinto dor, porque dói a minha \\
\hline \multirow{6}{*}{ Mal/Triste/Com Sintomas (18) } & $\begin{array}{l}\text { "Triste, porque o Fábio não é meu } \\
\text { amigo" }\end{array}$ \\
\hline & $\begin{array}{l}\text { "Eu fico com tosse, com febre, } \\
\text { espirrando" }\end{array}$ \\
\hline & $\begin{array}{l}\text { "Eu sinto saudade da minha mãe, } \\
\text { porque eu sinto muita saudade dela. }\end{array}$ \\
\hline & Ela demora a chegar do trabalho dela" \\
\hline & "Passando mal" \\
\hline & "Eu fico \\
\hline Não sente nada (1) & "Nada" \\
\hline Não soube informar (3) & "Eu não sei" \\
\hline
\end{tabular}

Quando indagadas sobre "Quem você espera encontrar quando chega à escola?", os relatos das crianças destacaram a figura dos seus pares, representados aqui pela categoria colegas/amigos (20). Em menor proporção foram apontados também os parentes (10). Enquanto que, entre as categorias menos mencionadas pelas crianças estão objetos, brinquedos e animais (1). 
Tabela 3.

Frequência das categorias que descrevem quem ou o quê as crianças esperaram encontrar ao chegarem à escola, segundo dados coletados na ECCSI. Belém, $2012(n=46)$.

\begin{tabular}{ll}
\hline Categorias & Visão das Crianças \\
\hline Colegas/Amigos (20) & "Um monte de amiguinho" \\
"Meus coleguinhas" & "Minha professora" \\
Professoras (9) & "Alguma professora" \\
Parentes (10) & $\begin{array}{l}\text { "(..) A minha irmã estuda aqui do o meu irmão estuda lá em } \\
\text { cima, a minha prima também" }\end{array}$ \\
Objetos/brinquedos, & "O Tayimais sor, meu primo" \\
(1) & "Minha centopeia" \\
Comida (2) & "Biscoito" \\
Ninguém (4) & "Bombom" \\
Não soube informar (2) & "Ninguém" \\
\hline
\end{tabular}

\subsubsection{Escola: rotinas e atividades de preparação de volta pra casa}

Os dados mostram que na preparação para ir à escola ou voltar para casa, em geral, as crianças realizaram as mesmas atividades: acordar, tomar banho, escovar dentes, vestir a roupa, calçar sapatos, preparar/ servir a refeição, alimentação e organizar o material escolar. O que parece ter mudado nesse processo foram justamente as relações estabelecidas nesse novo contexto. Quanto às atividades de preparação de volta a casa, observou-se que as crianças informaram realizar as atividades pentear o cabelo e vestir a roupa (45); escovar os dentes, calçar os sapatos e alimentação (44); tomar banho, e organizar o material escolar (43); acordar (41); e preparar/servir a refeição (39).

$\mathrm{Na}$ Tabela 4, observa-se que as três categorias de respostas mais mencionadas pelas crianças referindo-se à sua preparação de volta da escola pra casa, com a frequência total das menções referentes às atividades realizadas, foram: sozinha (253), professora (123), e colega (9), enquanto que as menos mencionadas foram amigo(a) (2) e outros (7). 
Tabela 4.

Pessoas/companhia da criança por atividades relatadas no período na escola, para voltar pra casa, segundo dados coletados na ECCSI. Belem, $2012(n=46)$.

\begin{tabular}{llllllll}
\hline $\begin{array}{l}\text { Quem prepara } \\
\text { Atividades }\end{array}$ & Professora & Colega & Amigo & Outros & Sozinha & NSI & NRA \\
\hline Acordar & 15 & 4 & 1 & 1 & 20 & 4 & 1 \\
Tomar banho & 24 & 3 & 1 & & 17 & 3 & \\
Escovar dentes & 7 & & & & 38 & 2 & \\
Pentear o cabelo & 30 & 4 & & & 15 & 1 & \\
Vestir roupa & 4 & & & 42 & 1 & \\
Calçar sapatos & 6 & & & 38 & 2 & \\
Preparar/servir & 19 & 1 & & 5 & 14 & 7 & \\
refeição & 5 & & & & 40 & 2 & \\
Alimentação & 5 & 1 & & 1 & 29 & 3 & \\
Organizar & 13 & 9 & 2 & 7 & 253 & 25 & 1 \\
material escolar & 123 & 9 & & & &
\end{tabular}

"NSI: não soube informar; NRA: não realiza a atividade.

A Tabela 5 mostra as respostas emitidas pelas crianças quando perguntadas "Como você se sente quando está saindo da escola e voltando pra casa?". Nela, verifica-se que as crianças expressaram de forma mais acentuada sentimentos e emoções representados pela categoria bem estar/alegria (23). De modo menos frequente, foram apontados sentimentos que expressam a sua insatisfação por estar nos preparativos para o seu retorno à família, como o indicado pela categoria mal estar/tristeza (16). 
Tabela 5.

Categorias que descrevem os sentimentos relatados pelas crianças relacionados ao período de preparação na escola para retorno à familia, segundo dados coletados na ECCSI. Belém, $2012(n=46)$.

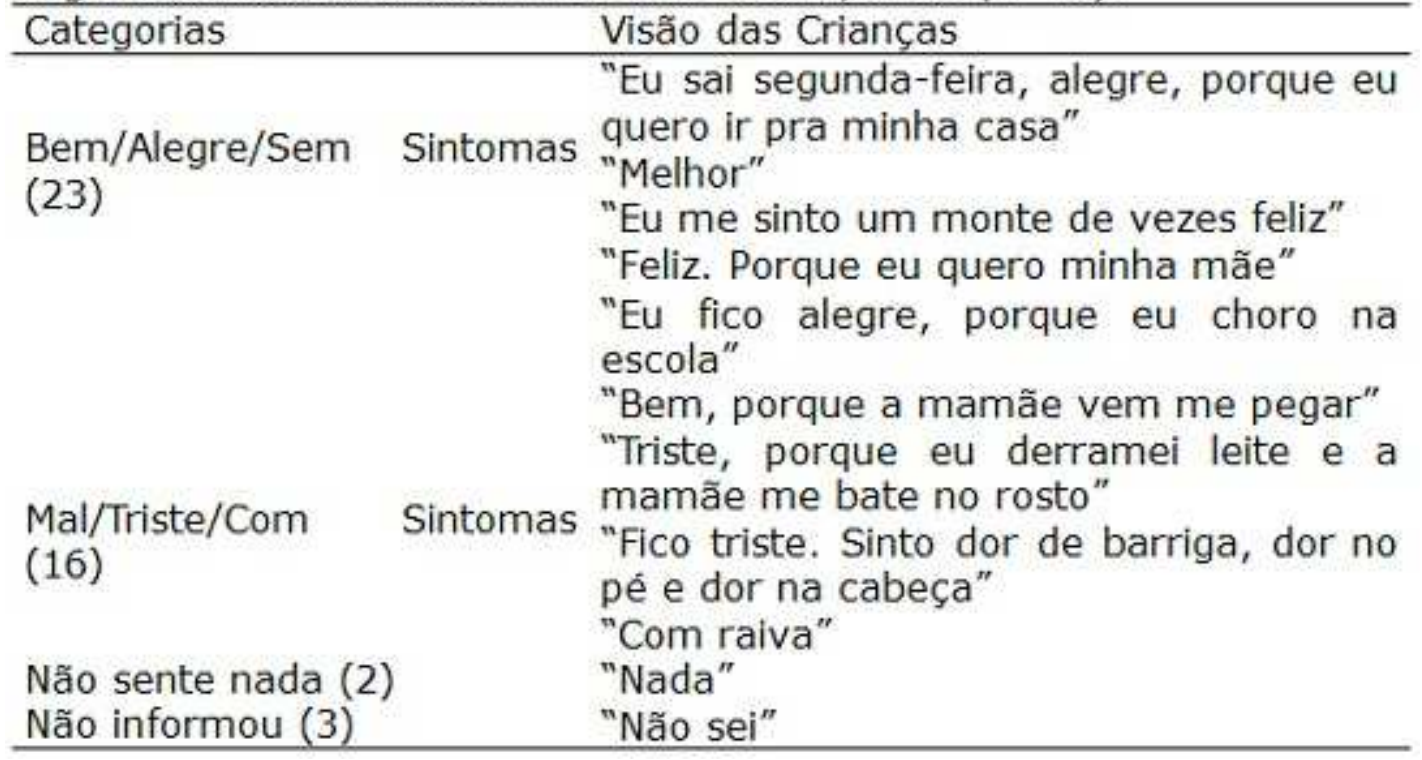

\subsubsection{No Trajeto da Escola-Família (TEF): o que faz e como se sente}

Conforme as respostas dadas à pergunta "Quem acompanha você no caminho da escola pra casa?", as companhias mais mencionadas pelas crianças foram: mãe (33), pai (13), pais (4) e outros (4), por sua vez, as companhias menos mencionadas foram avós (1), irmã (1) e avó (2). Já quanto ao meio de transporte, observa-se que quando perguntado às crianças "Como você volta da escola pra casa?", os três transportes mais citados foram: bicicleta (19), a pé (15) e carro (14), já os transportes menos mencionados foram moto (4) e ônibus (12).

Na Tabela 6, vê-se que quando as crianças foram perguntadas sobre "Quem você espera encontrar quando chega em casa?", elas responderam de forma mais frequente respostas reunidas em categorias como: pais (23), avós (9) e irmãos (8). Enquanto que as menos lembradas foram: ninguém (2), animais (3) e comida (3). 
Tabela 6.

Frequência das categorias que descrevem quem ou o quê as crianças esperam encontrar no retorno à Familia, segundo dados coletados na ECCSI. Belém, $2012(n=46)$.

\begin{tabular}{|c|c|}
\hline Categorias & Visão das crianças \\
\hline \multirow[t]{3}{*}{ Pais (23) } & "Minha mãe" \\
\hline & "Papai, mas ele chega só de noite" \\
\hline & "A minha mãe e o meu pai" \\
\hline Irmăos (8) & "Meu irmão e a minha irmă" \\
\hline \multirow[t]{2}{*}{ Avós (9) } & "Vovō" \\
\hline & "Com o meu avô" \\
\hline Tios (4) & "Com o titio $(\ldots)$ " \\
\hline Colegas, amigos, vizinhos & "Rafael, que mora na frente da minha casa" \\
\hline $\begin{array}{l}\text { Objetos/brinquedos, } \\
\text { animais ( } 3 \text { ) }\end{array}$ & $\begin{array}{l}\text { "Eu quero ver o carro }(\ldots) \text { " } \\
\text { "Um bicho" }\end{array}$ \\
\hline Comida (3) & "Meu Danone" \\
\hline Ninguém (2) & "Ninguém" \\
\hline Não soube informar (3) & "Não sei" \\
\hline
\end{tabular}

Dados referentes às respostas dadas pelas crianças quando perguntadas "Como você se sente quando está chegando em casa?" são apresentados na tabela 7 . Verficou-se que as crianças mencionaram mais sentimentos relacionados ao bem estar/alegria (24) do que aqueles que podem ser compreendidos como mal estar/tristeza (16).

Tabela 7.

Categorias que descrevem os sentimentos relatados pelas crianças referentes ao período em que estão retornando à Familia depois da Escola (FDE), segundo dados coletados na ECCSI. Belém, $2012(n=46)$.

\begin{tabular}{ll}
\hline Categorias & Visão das Crianças \\
\hline & "Me sinto melhor, feliz" \\
& "Melhor, eu não sel explicar. Alegre porque eu \\
& estou com a minha mamãe e com meus \\
irmãos" & "Alegre, porque eu tava doente lá na escola" \\
& "Eu me sinto bem, porque amanhã eu não \\
& venho pra aula. Eu não quero vir pra aula, eu \\
Bem/Alegre/Sem & quero ir pra casa da vovó" \\
Sintomas (24) & "Eu chego em casa com a minha mãe triste. \\
Mal/Triste/Com Sintomas & Quando eu chorei e a minha mãe não bota \\
(16) & jogo dos três porquinhos" \\
& "(...)Triste, porque o Jacó, meu primo, me \\
bate" & "É com dor de cabeça e febre" \\
Não sente nada (5) & "Eu não sinto nada" \\
Não soube informar (2) & "Não sei"
\end{tabular}




\subsubsection{Na Família Depois da Escola (FDE): o que faz e como se sente quando chega em casa}

Os resultados mostram que quando as crianças foram indagadas com perguntas a exemplo de "Como você se sente quando está de volta em casa?", as crianças mencionaram mais sentimentos relacionados ao bem estar/alegria (30), do que os que expressam manifestação de mal estar/tristeza (12).

Tabela 8.

Frequência das categorias que drescrevem os sentimentos relatados pelas crianças referentes ao periodo Familia Depois da Escola (FDE), segundo dados coletados na ECCSI. Belém, $2012(n=46)$.

\begin{tabular}{ll}
\hline Categorias & Visão das Crianças \\
\hline & "Eu me sento com o meu pai comendo \\
& cupuaçú, eu me sinto bem, porque eu \\
estou feliz" & "Melhor, fico feliz e alegre, porque sim" \\
Bem/Alegre/Sem Sintomas (30) & "Nada. Alegre, porque sim, eu não \\
& queria ir pra escola" \\
& "Me sinto com dor de barriga, porque a \\
& mamãe não deixa eu tomar meu \\
remédio" & "Eu fico com febre, triste, porque a \\
Mal/Triste/Com Sintomas (12) & minha mãe me bate, porque eu choro, e \\
& quando eu dormo a minha mãe me \\
acorda" & \\
Não sente nada (2) & "Nada" \\
Não soube informar (3) & "Não sei"
\end{tabular}

\section{Discussão}

Com este estudo, verificou-se que são vários os membros da família que contribuem com as atividades diárias de preparação da criança para ida à escola, incluindo o despertar, a higiene corporal e o desjejum. As crianças destacaram a mãe e o pai como os cuidadores mais presentes nessas rotinas diárias. Silva e Tokumaru (2008), em estudo anterior, mostraram que as figuras parentais compartilham mais os cuidados com os filhos do que outros membros da família na mesma condição, sendo esta, contudo, uma prática observada com mais frequência entre alunos matriculados em escola pública do que de instituições particulares.

Segundo Ecke (2010), historicamente tem sido função dos pais educar e preparar a criança para o estabelecimento de outras 
relações além do meio familiar, como acontece quando do seu ingresso na escola. À medida que a criança vai crescendo cabe então aos pais auxiliá-la no desenvolvimento do senso de autonomia, independência e responsabilidade que irá favorecer 0 seu engajamento em atividades e papeis decorrentes dessas novas relações. É esperado que os pais, ou qualquer um deles, por meio de rotinas estabelecidas possam apoiar a criança no desenvolvimento de habilidades importantes para o seu convívio em ambientes que se diferenciam do familiar a partir de práticas de cuidado e/ou a supervisão das atividades de vida diária. Nessa direção, os resultados mostram ainda que, além dos pais, a figura da avó tem se apresentado de forma recorrente nesse tipo de investigação, tendo sido destacada sua presença pelas crianças que participaram deste estudo. Mais uma vez estes dados corroboram achados de Silva e Tokumaru (2008) por terem realçado a participação das avós nas rotinas de cuidado infantil, apontando para a importância do parentesco entre o alocuidador e a criança, o que aumenta a chance de ser atendida em suas demandas, e de forma mais estável.

A literatura chama atenção igualmente para o valor da presença das figuras parentais ou de outros cuidadores habituais que assumem a função de acompanhar a criança no processo pelo qual transita entre diferentes ambientes e percebe as variações temporais (Ecke, 2010). Os dados da pesquisa mostram que as crianças iam à escola e voltavam para casa sempre acompanhadas de algum membro da família: mãe (36), pai (11), pais (5) e avó (5). Apenas duas disseram ir e voltar da escola sem a companhia de alguém da família, no caso, sozinhas (2). Estes dados remetem à consideração de que, especialmente no início da vida escolar quando a criança precisa se deslocar de casa pra escola e da escola pra casa (McDonald \& Aalborg, 2009; Ecke, 2010), a família tende a se sentir mais responsável por essa supervisão.

Neste estudo, observou-se que as crianças que demonstraram mais sentimento de bem-estar/alegria nesse processo de transição no vivido cotidiano foram aquelas que: 1 ) lembraram do envolvimento da mãe ou do pai em seu processo de preparação para ir à escola 2) reconheceram a possibilidade de no ambiente escolar conseguirem se relacionar com outras pessoas 3 ) demonstram satisfação consigo mesmas por não haverem chorado ou qualquer outra forma de protesto por ter que ir ou ficar na escola. Estes achados remetem às contribuições trazidas por pesquisas sobre a importância das interações e relações entre pares. Segundo Ladd (2012, p. 9), "crianças que já têm habilidades para fazer amigos e comportamentos cooperativos têm melhores chances de construir relacionamentos aprobativos no contexto escolar e que possam ajudá-las a ter sucesso na pré-escola e no ciclo inicial do ensino fundamental". O autor destaca o potencial relacional que as crianças 
têm nessa fase do desenvolvimento, e também o quanto elas são capazes de identificar expectativas relacionais neste no novo ambiente: a escola.

Quando indagadas como se sentiam no momento que marca a sua saída da escola, as crianças apresentaram uma visão positiva dessa experiência. A maior parte das respostas pode ser agrupada na categoria bem estar/alegria/sem sintomas, deixando claro que elas aguardavam com certa ânsia pelo momento de estar em casa e poder rever a mãe. Do mesmo modo, as crianças que enfatizaram os sintomas e/ou a sensação de mal estar/tristeza com a proximidade de casa, ficando claro que algumas se sentiam insatisfeitas no momento em que retornavam à família e viviam com isso uma nova mudança de ambiente ao final do dia. Do mesmo modo, verificou-se que a participação da família parece estar relacionada à expressão de bem estar/alegria das crianças nesse processo, como haviam destacado Kagan (2008) sobre a importância dos pais e dos avós na preparação das crianças especialmente nesse momento inicial da vida escolar, por ser este um processo dinâmico que requer a participação contínua da família, da escola e da comunidade. É importante destacar ainda que as crianças participantes da pesquisa que destacaram mal estar/tristeza, associaram este sentimento à aspectos da qualidade da relação que mantinham com a mãe (agressiva, com a presença de episódios de violência), além de mencionarem sintomas de doenças, que, como discute Rizzo (2000) podem ser vistos como sinais de alertas para dificudades de adaptação às mudanças havidas com o seu ingresso na escola.

Vogler, Crivello e Woodhead (2008) consideram que as transições exigem importantes ajustes psicossociais e culturais, cognitivos, sociais e emocionais, que dependerão da natureza e as causas da mudança que está em processo, da vulnerabilidade ou resiliência dos indivíduos envolvidos e do grau de mudança e continuidade nas experiências vivenciadas. Desse modo, entende-se que as relações familiares, como por exemplo, a relação com a mãe, pode influenciar o emocional das crianças no período de inserção delas na escola. Isso depende, contudo, da forma como tais experiências forem vivenciadas e assimiladas pela criança como pessoa em desenvolvimento e a forma como a família e a escola irão agir em relação às suas demandas nesse momento.

Outro aspecto a ser ressaltado diz respeito à definição e redefinição de papeis nesse período de transição ecológica: na Escola $(E)$, quando da sua preparação para volta à família, as crianças pareceram desempenhar com mais autonomia as atividades de autocuidado que faziam parte das rotinas estabelecidas neste novo ambiente ecológico. Entre as prováveis razões para isto, pode ser citado o fato de que crianças nessa faixa etária são estimuladas a realizar atividades de vida diária (especialmente, as atividades de 
autocuidado) com mais autonomia, ou ainda, pelo número insuficiente de educadores diante do quantitativo de crianças por turma. No ambiente escolar, as atividades tendem a exigir da criança uma maior autonomia na sua realização, o que corrobora Dowbor (2008) quando afirma que tanto a família, como a escola, são instituições sociais responsáveis pela formação e estruturação de indivíduos.

Os resultados apresentados remetem à presença de uma característica que pode ser explicada pela própria lógica que preside as transições ecológicas (Bronfenbrenner, 1996, 2011): quando as crianças começam a estudar passam a ocupar na sociedade (o status de aluno) e muda a forma como se espera que ela venha a se comportar, pensar, agir (o papel de aluno). Entende-se, com isso, que a vivência de um novo papel por conta da inserção da criança como pessoa em desenvolvimento em um ambiente ecológico diferente tem uma representatividade muito particular e evidente, tanto para a sua condição de indivíduo como no que diz respeito às pessoas que a cercam.

\section{Considerações finais}

Com este estudo, foi possível verificar aspectos da vivência cotidiana dessa transição ecológica por 46 crianças de uma instituição de educação infantil localizada em Belém. Espera-se que seus resultados possam contribuir com a investigação desta que tem sido vista como uma das mais influentes transições vividas na infância, reafirmando achados e conclusões da literatura existente. Este estudo pode ser útil para ampliar o conhecimento sobre esta e outras transições vividas na infância, com destaque para o processo de adaptação da criança à escola no início da vida escolar. De todo modo, pode-se dizer que o aspecto inovador deste trabalho reside na busca por olhar o processo de adaptação da criança à escola como um processo de transição entre dois dos mais influentes ambientes ecológicos nos anos iniciais do desenvolvimento humano, especialmente nas sociedades ocidentais e urbanas como é o exemplo brasileiro.

Por este estudo, procuramos afirmar outra tendência hoje colocada na área da Psicologia do Desenvolvimento, qual seja: dar voz às crianças em pesquisas, as quais tomam como objeto de estudo aspectos do universo infantil. Sugere-se a realização de novas investigações que possam tomar como objeto de estudo esta e outras transições ecológicas. Com a realização deste estudo, observou-se em relação às dificuldades, que houve variação de tempo durante a aplicação do questionário, algumas crianças necessitaram de mais tempo para responder do que outras, além de algumas crianças faltarem durante o período coleta, o que limitava as entrevistadoras a 
agirem de acordo com a disponibilidade e motivação das crianças para a conclusão do estudo, que a literatura sobre transições ecológicas é ainda insipiente, especialmente no Brasil. Além disso, quando se considera o início da vida escolar em uma perspectiva desenvolvimental, vê-se o quanto seriam oportunas investigações sobre essa forma particular de transição ecológica, não apenas de crianças, mas, também, de jovens e adultos, que se constitui uma realidade atual na sociedade brasileira.

\section{Referências}

Bronfenbrenner, U. (1996). A ecologia do desenvolvimento humano: experimentos naturais e planejados (M. A. V. Veronese, Trad.). Porto Alegre: Artes Médicas. (Original publicado em 1979)

Bronfenbrenner (2011). Bioecologia do Desenvolvimento Humano. Porto Alegre: Artmed.

Campos, M. M. (2008). Por que é importante ouvir a criança? A participação das crianças pequenas na pesquisa científica. In: S. H. V., Cruz (Org.). A criança fala: a escuta de crianças em pesquisas, (pp.35-420). São Paulo: Cortez.

Cruz, S. H. V. (2010). Ouvir crianças: uma tarefa complexa e necessária. In: M. P. R. Souza (org.). Ouvindo crianças na escola: abordagens e desafios metodológicos para a psicologia. (pp. 11-21). São Paulo: Casa do Psicólogo. 1. ed.

Dowbor, F. F. (2008). Quem educa marca o corpo do outro. 2. ed. São Paulo: Cortez.

Ecke, M. B. (2010). Influência das práticas educativas maternas no processo de adaptação dos filhos na educação infantil. Monografia de Especialização, Universidade Federal do Rio Grande do Sul, Porto Alegre, RS, Brasil.

Kagan, S. L. (2008). Transiciones exitosas: uma cuestión de preparación? La primera infância en perspectiva, 2, 1-71.

Ladd, G. W. (2012). Transições escolares/prontidão escolar: um resultado do desenvolvimento na primeira infância. In: R. E. Tremblay, M. Boivin M, \& R. de V. Peters (Eds). Enciclopédia sobre o Desenvolvimento na Primeira Infância [on-line]. Montreal, Quebec: Centre of Excellence for Early Childhood Development e Strategic Knowledge Cluster on Early Child Development; 2012:1-11. Recuperado em 15 de março, 2013, de: http://www.enciclopediacrianca.com/documents/LaddPRTxp1-Original.pdf

McDonald, N. C., \& Aalborg, A. E. (2009). Why parents drive children to school?: Implications for Safe Routes to School Programs. Journal of the American Planning Association, Summer, 75(3), p. 331-342. 
Nunes, N. N. (2012). O ingresso na pré-escola: uma leitura psicogenética. In: I. Z. M. Oliveira (Org.). A criança e seu desenvolvimento: Perspectivas para se discutir a educação infantil. (pp. 114-142). 5. ed. São Paulo: Cortez.

Rizzo, G. (2000). Creche: organização, montagem e funcionamento. Rio de Janeiro: Francisco Alves.

Silva, L. W., \& Tokumaru, R. (2008). Cuidados Parentais e Aloparentais Recebidos por Crianças de Escolas Públicas e Particulares de Vitória - ES. Psicologia: Reflexão e Crítica, 21(1), p. 133-141.

Vogler, P., Crivello, G., \& Woodhead, M. (2008). La investigación sobre las transiciones em la primera infancia: Análisis de nociones, teorías y prácticas. Cuadernos sobre Desarrollo Infantil Temprano. Bernard van Leer Foundation.

\section{Endereço para correspondência}

Maureanna Cardoso Alvão

Universidade Federal do Pará

Programa de Pós-Graduação em Teoria e Pesquisa do Comportamento

Rua Augusto Corrêa, 01, Campus Universitário do Guamá, CEP 66075-110, Belém, PA, Brasil

Endereço eletrônico: maureanna@gmail.com

\section{Lília Iêda Chaves Cavalcante}

Universidade Federal do Pará

Programa de Pós-Graduação em Teoria e Pesquisa do Comportamento

Rua Augusto Corrêa, 01, Campus Universitário do Guamá, CEP 66075-110, Belém, PA, Brasil

Endereço eletrônico: liliaccavalcante@gmail.com

Recebido em: 20/06/2014

Reformulado em: 14/04/2015

Aceito para publicação em: 16/05/2015

\section{Notas}

* Psicóloga Mestre pelo Programa de Pós-Graduação em Teoria e Pesquisa do Comportamento da Universidade Federal do Pará, Belém/Brasil.

** Docente do Programa de Pós-Graduação em Teoria e Pesquisa do Comportamento da Universidade Federal do Pará. 